\title{
Real exchange rates and real interest rates : a nonlinear perspective
}

\author{
Frédérique Bec* \\ CREST-ENSAE** \\ Mélika Ben Salem* \\ OEP, Université de Marne-la-Vallée, France*** \\ Ronald MacDonald* \\ University of Glasgow, Scotland
}

\section{Introduction}

The stationarity properties of real exchange rates have received intense scrutiny over the last decade (for literature overviews see Froot and Rogoff (1995), MacDonald (1995) or Rogoff (1996)). One stylised fact to emerge from this literature is that, when defined on a single currency basis for the recent floating period, real exchange rates are non-stationary. This result may be overturned if the data sample is extended to around one hundred years of annual data, or if the stationarity test is conducted in a panel context. Nevertheless, even in these instances the speed of mean reversion is regarded as being too slow to be consistent with a traditional form of PPP (a half-life of approximately four years is the adjustment speed recovered from these kinds of test). There are essentially two responses to this result. The first is to abandon strict PPP and focus explicitly on the 'real' determinants of real exchange rates. This research avenue has begun to yield interesting results (see, for example, Mark (1999)).

The second response to the slow mean reversion in real exchange rates has involved an explicit recognition of the importance of transaction costs in introducing nonlinear behaviour into real exchange rates. A number of studies have therefore utilized variants of threshold autoregressive (TAR)

* We wish to thank, with usual disclaimers, two anonymous referees for very useful comments on a previous version of this work. Fréderique Bec is grateful to the funding by Danish Social Sciences Research Council (2114-04-0001).

** CREST-ENSAE, 3 avenue Pierre Larousse, 92245 Malakoff Cedex, France. Email : bec@ensae.fr

*** Email : melika.bensalem@univ-mlv.ir

**** Email : r.macdonald@socsci.gla.ac.uk 
models to capture such behaviour (see, for example, Michael, Nobay and Peel (1997) and Obstfeld and Peel (1997)). These studies show considerable promise in the sense that there do indeed appear to be important nonlinearities in the time series properties of real exchange rates, and once this has been modeled the speed of mean reversion is quite fast and consistent with a traditional form of PPP (see, for example, Obstfeld and Peel (1997)). However, as will be discussed in the next section, one issue in studies which use the TAR approach concerns the stationarity of the variable used to define the threshold, namely the real exchange rate. This could mean that some recent TAR-based modelling of the real exchange rate are suspect. One way to overcome this issue is to define the threshold in terms of a stationary variable. The tests and distribution theory recently developed by Caner and Hansen (2001), which allow for the joint consideration of nonlinearity and nonstationarity, are well-suited to such an approach. In the case of the real exchange rate analysis, a natural candidate arises from the well-known uncovered interest rate parity relation, namely the real interest rate differential. This choice is further motivated by the general equilibrium model proposed by Dumas (1992). Our work may therefore be seen as combining two recent strands in the real exchange rate literature - that which introduces extra information into the prediction of the real exchange rate, over-and-above its lagged history, and recent advances in nonlinear modeling, of possibly, nonstationary time series data. The outline of the remainder of this paper is as follows. In the next section we briefly overview existing analysis of the real exchange rate in a nonlinear context. We also present theoretical justification for using the information conveyed by the real interest differential in a threshold autoregressive model. Section 3 then details the proposed threshold autoregressive model, as well as the corresponding linearity and unit root tests. Our results are presented in Section 4 and some concluding comments are contained in Section 5 .

\section{Rationale For The Real Exchange Rate Nonlinear Behaviour}

As noted in the introduction, recent research which uses linear models to capture the time series properties of real exchange rates produces mean reversion speeds which are too slow to be consistent with a traditional form of PPP. For example, a number of studies (see Froot and Rogoff (1995) and MacDonald (1995) for overviews) indicate that for the recent floating period real exchange rates contain a unit root ${ }^{1}$. How then may the nonstationarity of real exchange rates be resolved ? One response is to consider a 'linear' cointegration-based approach in which the interaction of a real

1 Even tests of fractional integration do not seem to be able to reject the unit root - see e.g. Henry and Olekalns (2002). 
exchange rate with a set of $\mathrm{I}(1)$ fundamentals - such as net foreign assets and productivity differences - produces a stationary linear combination, or cointegrating vector. Such studies are clearly not in the spirit of PPP as they explicitly recognise that there may be persistent trends in real exchange rates.

An alternative way of resolving the 'PPP puzzle' (Rogoff (1996)) has involved recognising the implications that transaction costs can have for the time series properties of the real exchange rate. It has been widely recognised, at least since Cassel, who is regarded as providing the version of PPP on which most recent work is based, that transaction costs can generate a neutral band within which it is unprofitable to arbitrage away deviations from PPP (or non-zero values of the real exchange rate) and Krugman (1989) has emphasised the importance of spatially separate locations in determining such costs. Introducing shipping costs into two-country general equilibrium models (e.g. Dumas (1992), Uppal (1989), Sercu, Uppal and Van Hulle (1995) or Berka (2004)) generates a nonlinear, typically two-regime dynamics for the real exchange rate process. Basically, these models predict the existence of a no-trade region within which the real exchange rate adjustment toward the PPP equilibrium, if any, is expected to be slow. In this region, $\mathrm{PPP}$ deviations in absolute value are small compared to the shipping costs. Below and above this no-trade area, i.e. when PPP departures are larger than trading costs in absolute value, international trade is triggered which provides an error-correction mechanism that brings the real exchange rate back inside the no-trade area. Recently, researchers have begun to test this implication for the behaviour of real exchange rates. For example, Michael, Nobay and Peel (1997) and Kilian and Taylor (2003) apply the exponentially autoregressive (EAR) model of Haggan and Ozaki (1981) (see also Granger and Terasvirta (1993)) and Obstfeld and Peel (1997) use a band threshold autoregressive (B-TAR) model to capture the kind of nonlinear behaviour imparted into real exchange rates by transaction costs. ${ }^{2}$

The above-noted papers produce interesting evidence of relatively rapid mean reversion when nonlinear methods are used. However, the treatment of non-stationarity raises important questions. In particular, the stationarity of the switching variable is essential because it is necessary that the process visits every regime infinitely often. If it is not stationary the process has a certain probability to be absorbed, into a single regime, and in this case there are no relevant asymptotics for the other regimes. ${ }^{3} \mathrm{~A}$ related issue is that the tests of linearity versus a threshold alternative used in these studies assume that the series is stationary. So, the empirical results found regarding nonlinearity and mean-reversion must be interpreted cautiously unless a proper test of unit root against a stationary threshold

2 By contrast, the Markov-Switching autoregressive class of models has been less explored so far (see e.g. Bessec (2002) or Bergman and Hansson (2005)). The reason for this is likely that estimation is based on filtering algorithms, and a full asymptotic theory for inference still needs to be explored, even though much progress in that direction has been made in a recent paper by Douc, Guillin and Moulines (2004).

3 We thank $R$. Tsay for establishing this point in private correspondence. 
alternative has been performed. Unfortunately, recent studies by e.g. Enders and Granger (1998), Pippenger and Goering (2000) or Taylor (2001) have shown that standard unit-root tests have low power in the presence of nonlinear adjustment.

In a recent paper Caner and Hansen (2001) develop both unit root and linearity tests based on models where the threshold variable is stationary and differs from the dependent variable under the alternative hypothesis ${ }^{4}$. We therefore propose combining the two research strands that have emerged in the recent exchange rate literature : the nonlinear TAR framework, along with the idea that there are real forces driving the real exchange rate. From a statistical point of view, a crucial assumption maintained in Caner and Hansen (2001) methodology is that the switching variable must be stationary, which reduces the number of relevant candidates. From economic theory, the most obvious candidate compatible with this stationarity requirement seems to be the real interest rate differential. Actually, rationale for this choice comes both from the arbitrage approach, using the uncovered interest rate parity (UIP) relation, and from the general equilibrium approach, as in the Dumas (1992) model. From the arbitrage approach, the choice of the real interest rate differential stems from the UIP relationship expressed in real terms :

$$
E_{t}\left(z_{t+k}-z_{t}\right)=-\left(E_{t} r_{t}-E_{t} r_{t}^{*}\right)
$$

where $E_{t}$ is the conditional expectations operator, $z_{t}$ is the real exchange rate (defined as the foreign currency price of home currency), $r_{t}$ is the real interest rate and an asterisk denotes a foreign magnitude. ${ }^{5}$ Expression (1) simply states that the evolution of the expected change in the real exchange rate is governed by (the negative of) a real interest differential. Rearranging (1) produces an equilibrium relationship for the real exchange rate as:

$$
z_{t}=E_{t} z_{t+k}+\left(E_{t} r_{t}-E_{t} r_{t}^{*}\right)
$$

where the real exchange rate is determined by the expected future real exchange rate and the expected real interest differential. In studies which exploit (2) as an equilibrium relationship, it is often assumed that the expected real exchange rate is a measure of the equilibrium real exchange rate, $\bar{z}_{t}$. Two assumptions are usually made regarding $\bar{z}_{t}$ : either it is assumed to be constant, or, alternatively, a function of variables which are supposed to impart systematic variability into the equilibrium real exchange rate, such as the Balassa-Samuelson productivity effect or net foreign asset accumulation.

Empirical tests which assume the equilibrium real rate is constant, focus on the following regression equation :

$$
z_{t}=\beta_{0}+\beta_{1}\left(r_{t}-r_{t}^{*}\right)+\phi_{t},
$$

4 See also Gonzalez and Gonzalo (1998) or Shin and Lee (2001) on this point.

5 Expression (1) could also be written with the addition of a time-varying risk premium. However, since this would not materially affect the following discussion we do not include it here. 
which may be derived from (2) by assuming $\bar{z}_{t}=\beta_{0}$. Recent empirical estimates of $(3)$ have used cointegration methods to test the stationarity of the error term. However, the empirical evidence in favor of (3) is rather weak. For example, a number of researchers have used the Engle-Granger two-step cointegration method (see, for example, Meese and Rogoff (1988), Edison and Pauls (1993), Throop (1994) and Coughlin and Koedijk (1990) ${ }^{6}$ ), and have failed to reject the null hypothesis that $\phi_{t}$ is an $I(1)$ process. Using the methods of Johansen, there is some evidence that the null may be rejected (see, for example, Edison and Melick (1999) and MacDonald (1999)), although the source of the rejection appears to arise from the stationarity of the interest differential rather than cointegration between the real exchange rate and the real interest differential.

Studies which assume $\bar{z}_{t}$ to be a function of variables such as e.g. productivity effects, fiscal imbalances, net foreign asset accumulation and terms of trade effects (see, for example, Gagnon (1996), MacDonald (1999), Mark (1999), Schnatz, Vijselaar and Osbat (2004), Alexius (2005)) provide rather mixed evidence. Note that since the variables assumed to be driving $\bar{z}_{t}$ are themselves non-stationary, they are not relevant for our approach. Indeed, our objective in this paper is to use the relationship between real exchange rates and real interest differentials, and particularly the stationary nature of the real interest differential, to define the threshold in our TAR study.

The choice of the real interest rate differential is also consistent with Dumas's (1992) general equilibrium model which introduces proportional trading costs. Indeed, this model predicts a close relationship between the interest rate differential and the real exchange rate. As stressed by Dumas, p. 176, "The risk premium notwithstanding, a large real-rate differential remains an indication of strong expected reversion in the law of one price (LOP) deviation. Shipping is triggered when the interest-rate differential reaches its largest possible value; this is also when the deviation from the LOP reaches its largest possible value. Deviations from PPP and deviations from equality of real interest rates are part and parcel of the same phenomenon." In this model, both the real exchange rate and the real rate differential dynamics are fundamentally determined by cross-country capital imbalances. An increase in the latter induces an increase in the relative price of the home and foreign goods as well as a larger real rate differential. This, in turn, translates into a higher than expected exchange rate change. Then, in a manner quite similar to the "honcymoon" effect identified by Krugman (1991) in his target-zone model, the expectation that shipping will eventually prevent the relative price from escaping the nontrading area makes the real exchange rate taper off as it approaches the boundaries. Even though the nonlinear relationship found by Dumas (1992) between the real-rate differential and real exchange rate does not take the

6 Coughlin and Koedijk (1990) find some evidence for cointegration for one of the currencies in their data set, namely the German mark-US dollar. 
form of a TAR model, this theoretical result suggests the use of the real-rate differential as the switching variable in the threshold model proposed in the next section ${ }^{7}$.

To our knowledge, this kind of nonlinear relationship has not yet been explored empirically. We believe that the combination of transaction costs and capital account interactions to explain deviations from PPP is entirely consistent with Cassel's interpretation of PPP, where the role of both interest differentials and transaction costs were recognised as preventing PPP holding continuously (see, for example, Officer (1976)).

\section{The TAR Model : A Nonlinear Alternative}

In this section we outline the particular TAR model used in our empirical work and also discuss the appropriate form of hypothesis testing in the TAR framework.

\subsection{The TAR model and its estimation}

Formally, we consider the following TAR model :

$$
\Delta z_{t}=\left(\mu_{1}+\rho_{1} z_{t-1}+a_{1}(L) \Delta z_{t}\right) s_{t}+\left(\mu_{2}+\rho_{2} z_{t-1}+a_{2}(L) \Delta z_{t}\right)\left(1-s_{t}\right)+\varepsilon_{t}
$$

$t=1, \ldots, T$, where $z_{t}$ is the real exchange rate, $a_{i}(L)=a_{i 1} L+\ldots+a_{i p} L^{p}$ $(i=1,2)$ are lag polynomials of order $p$ and the $\varepsilon_{t}$ 's are mean zero random disturbances with standard deviation $\sigma$. The variable $s_{t}$ is zero-one valued, with $s_{t}=1$ if $\left|Z_{t-d}\right|>\lambda$ and $s_{t}=0$ otherwise. $Z_{t-d}$ is any predetermined stationary variable which governs the switch between regimes, and in our case this is the real interest differential. $\lambda$ is the threshold defining the band within which the real exchange rate process may be persistent due to the real interest differential being too small in absolute value. Indeed, following Dumas's theoretical result in which only the magnitude of the real rate differential matters, and not the sign, we consider the absolute value of this differential as the switching variable. Furthermore, following most theoretical and empirical studies mentioned in the previous section, the threshold is assumed to be symetric ${ }^{8}$. This amounts to assuming that the magnitude of trading costs is similar at home and abroad, which seems a reasonable approximation. We note that both $d$ and $\lambda$ are unknown, and

7 So far, existing econometric theory regarding nonstationary and/or nonlinear time series does not handle the precise kind of nonlinear relationship found by Dumas (1992). For instance, the real exchange rate heteroskedasticity property exhibited by this author cannot be explored within the framework developed by Caner and Hansen (2001).

A Accordingly, we use demeaned and/or detrended real-rate differential data in order to ensure that both positive and negative realizations of the process are observed. 
assume that $d \in[1,12]$ and that $\lambda$ lies in the interval $\Lambda=[\underline{\lambda}, \bar{\lambda}]$. Following Caner and Hansen (2001), the boundaries $\underline{\lambda}$ and $\bar{\lambda}$ are chosen such that at least $15 \%$ of the observations lie in each regime.

In estimating the models we follow Tsay (1998). More specifically, for each value of $d$, the TAR model (4) is estimated by least squares for all $\lambda \in \Lambda$. This produces the estimates of $\hat{a}_{i}(d, \lambda)(L), \widehat{\mu}_{i}(d, \lambda), \hat{\rho}_{i}(d, \lambda), \widehat{\varepsilon}(d, \lambda)$, for $i=1,2$. Let

$$
\widehat{\sigma}^{2}(d, \lambda)=\frac{1}{T} \Sigma_{1}^{T} \widehat{\varepsilon}_{t}(d, \lambda)^{2}
$$

be the least-squares estimate of $\sigma^{2}$ for fixed $d$ and $\lambda$. For fixed $d$, the leastsquares estimate of $\lambda$ is found by:

$$
\widehat{\lambda}(d)=\arg \min _{\lambda \in \Lambda} \widehat{\sigma}^{2}(d, \lambda) .
$$

Then, the least-squares estimate of $d$ is the value which minimizes the residual variance:

$$
\widehat{d}=\arg \min _{d} \widehat{\sigma}^{2}(\widehat{\lambda}(d)) .
$$

The least-squares estimates of the other parameters are then obtained for $\lambda=\widehat{\lambda}$ and $d=\widehat{d}$.

\subsection{Hypothesis testing}

The model represented in (4) belongs to the class of two-regime models analyzed by Caner and Hansen (2001). Following these authors, we utilize a Wald statistic to test for threshold effects. The test of linearity (no threshold effect) corresponds here to the joint hypothesis :

$$
\mathrm{H}_{0}:\left\{\begin{array}{l}
\mu_{1}=\mu_{2} \\
\rho_{1}=\rho_{2} \\
a_{1 j}=a_{2 j}, \quad j=1, \ldots, p
\end{array}\right.
$$

This test may be implemented using the following standard Wald statistics :

$$
W^{T}=W^{T}(\hat{\lambda})=\sup _{\lambda \in \Lambda} T\left(\frac{\hat{\sigma}_{0}^{2}}{\hat{\sigma}^{2}(\lambda)}-1\right),
$$

where $\hat{\sigma}_{0}^{2}$ is the residual variance from OLS estimation of the null linear model, and $\hat{\sigma}^{2}(\lambda)$ is the residual variance of $(4)$.

Caner and Hansen (2001) have shown that the asymptotic null distribution of this Wald statistic depends on nuisance parameters and is in general nonpivotal. Since the dependence on the data structure is complicated, critical values cannot be tabulated. Consequently, we follow Caner and Hansen (2001) by using two bootstrap approximations to the asymptotic distribution of this Wald statistic : an unconstrained one, and one which 
imposes a unit root under the null of linearity ${ }^{9}$. Indeed, Caner and Hansen have shown that the asymptotic distribution of the threshold test depends on the presence of nonstationarity in the data.

In the context of expression (4), it follows that the unit root condition retained by Caner and Hansen is :

$$
\mathrm{H}_{0}: \rho_{1}=\rho_{2}=0
$$

Here again the standard Wald statistic corresponding to (6) is the appropriate test. Nevertheless, the natural alternative:

$$
\mathrm{H}_{1}: \rho_{1}<0 \text { and } \rho_{2}<0
$$

is not the only interesting one. Caner and Hansen also examine the intermediate case of a partial unit-root alternative :

$$
\mathrm{H}_{2}:\left\{\begin{array}{l}
\rho_{1}<0 \text { and } \rho_{2}=0 \\
\text { or } \\
\rho_{1}=0 \text { and } \rho_{2}<0
\end{array}\right.
$$

Of particular interest for our empirical analysis is the first case where $\rho_{1}<0$ and $\rho_{2}=0$. In line with the economic theory mentioned above, this case implies mean-reversion in the real exchange rate process only in the area corresponding to large interest rate differentials in absolute value. Caner and Hansen (2001) propose two Wald statistics, $R_{1 T}$ and $R_{2 T}$, which have power against both $H_{1}$ and $H_{2}$ :

$$
R_{1 T}=t_{1}^{2} 1_{\left\{\hat{\rho}_{1}<0\right\}}+t_{2}^{2} 1_{\left\{\hat{\rho}_{2}<0\right\}} \text { and } R_{2 T}=t_{1}^{2}+t_{2}^{2}
$$

where $t_{1}$ and $t_{2}$ are the $t$ ratios for $\hat{\rho}_{1}$ and $\hat{\rho}_{2}$, respectively, derived from the OLS regression (4). In order to discriminate between $H_{1}$ and $H_{2}$, Caner and Hansen (2001) suggest examining the individual $t$ ratios, $t_{1}$ and $t_{2}$. This will prove particularly useful in order to discriminate between the two sub-cases of $H_{2}$, since only the first one is consistent with Dumas' model predictions. Although they are able to derive analytically the asymptotic distributions of these statistics, Caner and Hansen (2001) recommend calculating bootstrap $p$-Values, because of the substantial size distortions. In the case of a tworegime TAR model, Caner and Hansen (2001) show that the asymptotic null distribution of these four statistics depends on whether there is a true threshold effect (identified threshold case) or not (unidentified threshold case). As a result, two kinds of bootstrap $p$-Values could be calculated : with or without a threshold effect. Nevertheless, it appears from their MonteCarlo experiments that the rejection rates using the linear model under the null of a unit root are less sensitive to nuisance parameters. Here again, we

${ }^{9}$ See p. 1563-1564 therein for a detailed description of the bootstrap method. 
will follow their recommendation by calculating the unidentified threshold bootstrap.

Finally; for nonlinearity to be a plausible explanation for the apparent non-stationarity of the real exchange rate, both null hypotheses (5) and (6) should be rejected. Then, when the latter is rejected, it must be checked that rejection does not come from $\rho_{2}<0$ only.

\section{The Empirical Analysis}

\subsection{The data}

The real exchange rate series analysed in this study are multilateral CPIbased real effective exchange rate for the domestic country relative to its G7 partner countries. All of the foreign variables are defined in effective terms using the weights contained in the effective exchange rates.

We use two measures for the real interest rate differential, $Z_{t}$. The first (denoted $s r s_{t}$ ) consists of a three-month bond yield differential $\left(s r_{t}\right)$, and the second $\left(l r s_{t}\right)$ a ten-year bond yield $\left(l r_{t}\right)$. In order to make the nominal interest rate yields consistent with the monthly consumer price indices, we re-expressed the interest, rates as monthly yields. Our measure of the ex ante interest rate is constructed as the nominal rate minus a measure of expected inflation. We define the date- $t$ expected inflation as $\pi_{t}^{e}=\log \left(p_{t+1} / p_{t}\right)^{10}$. Therefore, the real interest rates differentials are:

$$
\begin{gathered}
s r s_{t}=\left(s r_{t}-\pi_{t}^{e}\right)-\left(s r_{t}^{*}-\pi_{t}^{* e}\right) \\
l r s_{t}=\left(l r_{t}-\pi_{t}^{e}\right)-\left(l r_{t}^{*}-\pi_{t}^{* e}\right) .
\end{gathered}
$$

These tests are implemented using monthly data spanning the period 1980 : 01-1997 : 12 for the G7 countries : United-States, Germany, UnitedKingdom, Japan, Italy, Canada and France ${ }^{11}$. This sample length corresponds to a homogeneous regime of the recent floating period. Indeed, by not considering data before 1980 we exclude the initial turbulent year of the ERM. Similarly, by stopping the sample in $1997: 12$, we aim to avoid any contamination in the run up to EMU.

10 We are well aware that this may constitute a poor measure of expected inflation. In empirical work, the core inflation rate - which is less volatile - is sometimes preferred as a proxy for the expected inflation. Unfortunately, we do not have these data at our disposal. More recently, St-Amant (1996) or Gottschalk (2001) use the structural VAR methodology to derive an estimate of expected inflation. Although promising, this approach requires further theoretical identifying hypothesis and as such, is beyond the scope of our work.

11 These series were obtained from the IMF Databank. 


\subsection{Preliminary tests of integration order}

We firstly checked the orders of integration of the real exchange rate series in the context of a linear autoregressive model using three statistics, namely ADF (Dickey and Fuller (1981)), PP (Phillips and Perron (1988)) and KPSS (Kwiatkowski, Phillips, Schmidt and Shin (1992)). The results are reported in Table 1 and indicate an inability to reject a unit root for almost every pair. The only currency for which the tests are not clear cut are the DM and FRF. These results are consistent with the TAR specification given in (4) above.

Table 1 : Tests of $I(1)$ or $I(0)$ for $z_{t}$

\begin{tabular}{l|cccc|cccc|ccc} 
currency & \multicolumn{4}{|c|}{$\mathrm{ADF}(\mathrm{k})$} & \multicolumn{4}{c|}{$\mathrm{PP}(\mathrm{l})$} & \multicolumn{3}{c}{ KPSS(l) } \\
& $\mathrm{k}$ & $\tau$ & $\tau_{\mu}$ & $\tau_{\tau}$ & $l$ & $Z(\tau)$ & $Z\left(\tau_{\mu}\right)$ & $Z\left(\tau_{\tau}\right)$ & $l$ & $\eta_{\mu}$ & $\eta_{\tau}$ \\
\hline USD & 2 & -0.02 & -1.43 & $\mathrm{~ns}$ & 1 & 0.03 & -1.20 & $\mathrm{~ns}$ & 4 & 2.46 & $\mathrm{~ns}$ \\
GBP & 2 & -0.17 & -2.37 & $\mathrm{~ns}$ & 1 & -0.06 & -1.85 & $\mathrm{~ns}$ & 4 & 1.65 & $\mathrm{~ns}$ \\
FRF & 1 & -0.76 & -2.74 & $\mathrm{~ns}$ & 1 & -0.90 & -2.68 & $\mathrm{~ns}$ & 4 & 0.35 & $\mathrm{~ns}$ \\
DEM & 2 & -0.53 & -2.40 & $-\mathbf{3 . 5 4}$ & 1 & -0.65 & -2.28 & -3.46 & 4 & -1.70 & 0.47 \\
CAD & 1 & -0.82 & -0.59 & $\mathrm{~ns}$ & 0 & -0.73 & -0.31 & $\mathrm{~ns}$ & 3 & 1.37 & $\mathrm{~ns}$ \\
ITL & 1 & 0.04 & -1.63 & $\mathrm{~ns}$ & 2 & -0.04 & -1.39 & $\mathrm{~ns}$ & 4 & 0.77 & $\mathrm{~ns}$ \\
JPY & 2 & 0.68 & -1.78 & $\mathrm{~ns}$ & 2 & 0.72 & -1.52 & $\mathrm{~ns}$ & 4 & 3.31 & $\mathrm{~ns}$ \\
\hline
\end{tabular}

'ns' refers to non significant deterministic trend component.

The lag length $(\mathrm{k})$ is chosen according to the BIC criterion.

The size of the Bartlett window (I) is obtained following Andrews (1991).

Since the real interest differential must be stationary in the TAR model, we also checked the order of integration of the real interest rate differentials. Using the same test statistics as above, the results reported in Table 2 were obtained. Interestingly, there is no evidence of a unit root in any of these series, although some require a deterministic trend to induce stationarity. In the case of series which are stationary around a constant, we demean the series before using it as a switching variable. For series which require a deterministic trend to induce stationarity we detrend the series before using it as a switching variable.

As a final preliminary test, we examine the homoskedastic properties of the residuals from the linear real exchange rate autoregressions. Using the tests proposed by White, Engle and Pagan we found some evidence of heteroskedastic residuals (in the German and Italian models) and in these cases the Wald statistic is adjusted for heteroskedasticity ${ }^{12}$.

12 When the residuals are found to be heteroskedastic, we use the heteroskedasticity-consistent covariance matrix estimator $\mathrm{HC} 3$ given by MacKinnon and White (1985), equation (12) p. 309. 
Table 2 : Tests of $I(1)$ or $I(0)$ for interest rate differentials

\begin{tabular}{|c|c|c|c|c|c|c|c|c|c|c|c|c|}
\hline & \multicolumn{4}{|c|}{$\operatorname{ADF}(k)$} & \multicolumn{4}{|c|}{$\mathrm{PP}(\mathrm{l})$} & \multicolumn{3}{|c|}{$\operatorname{KPSS}(1)$} & \\
\hline & $\mathbf{k}$ & $\tau$ & $\tau_{\mu}$ & $\tau_{\tau}$ & $l$ & $Z(\tau)$ & $Z\left(\tau_{\mu}\right)$ & $Z\left(\tau_{\tau}\right)$ & $l$ & $\eta_{\mu}$ & $\eta_{r}$ & \\
\hline & & & & & & $s r s_{t}$ & & & & & & \\
\hline US & 2 & -4.75 & ns & ns & 3 & -7.79 & ns & ns & 2 & 1.26 & ns & $\mathrm{I}(0)$ \\
\hline UK & 12 & -2.13 & ns & ns & 2 & -11.29 & ns & ns & 1 & 0.064 & ns & $\mathrm{I}(0)$ \\
\hline FR & 0 & -9.05 & ns & -9.79 & 2 & -7.99 & ns & -8.96 & 2 & 1.60 & 0.379 & $I(0)+t$ \\
\hline $\mathrm{DE}$ & 0 & -11.22 & -11.52 & -11.75 & 3 & -9.47 & -9.75 & -9.90 & 1 & 0.588 & 0.251 & $I(0)+t$ \\
\hline $\mathrm{CA}$ & 3 & -4.36 & -4.88 & -5.34 & 3 & -11.02 & -12.34 & -14.26 & 0 & 1.58 & 0.404 & $I(0)+t$ \\
\hline IT & 2 & -4.97 & ns & -6.40 & 3 & -7.36 & ns & -8.70 & 2 & 2.29 & 0.194 & $I(0)+t$ \\
\hline $\mathbf{J P}$ & 0 & -13.20 & -13.52 & ns & 3 & $\begin{array}{c}-12.35 \\
\operatorname{lr} s_{t}\end{array}$ & -12.61 & ns & 0 & 0.520 & 0.265 & $\mathbf{I}(0)$ \\
\hline US & 0 & -11.16 & ns & -11.63 & 3 & -9.66 & ns & -10.94 & 1 & 1.32 & 0.20 & $I(0)+t$ \\
\hline UK & 12 & -2.69 & ns & ns & 2 & -11.75 & ns & ns & 1 & 0.043 & ns & $\mathrm{I}(0)$ \\
\hline FR & 1 & -10.53 & ns & -11.01 & 2 & 9.99 & ns & -10.49 & 1 & 1.20 & 0.245 & $\mathrm{I}(0)+\mathrm{t}$ \\
\hline $\mathrm{DE}$ & 4 & -5.52 & ns & ns & 3 & -9.87 & ns & $\mathrm{ns}$ & 1 & 0.297 & 0.107 & $\mathbf{I}(0)$ \\
\hline $\mathrm{CA}$ & 3 & -5.05 & $\mathrm{~ns}$ & -6.70 & 3 & -12.09 & ns & -14.94 & 0 & 2.14 & 0.086 & $\mathrm{I}(0)+\mathrm{t}$ \\
\hline IT & 0 & -9.46 & -9.99 & -10.65 & 3 & -7.91 & -8.31 & -9.07 & 1 & 1.47 & 0.176 & $I(0)+t$ \\
\hline JP & 0 & -13.81 & -14.55 & $\mathrm{~ns}$ & 3 & -13.15 & -13.90 & ns & 0 & 0.321 & 0.118 & $\mathrm{I}(0)$ \\
\hline
\end{tabular}

'ns' refers to non significant deterministic component.

The lag length (k) is chosen according to the BIC criterion.

The size of the Bartlett window (l) is obtained following Andrews (1991).

\subsection{The TAR model}

We estimate model (4), using alternative measures of $Z_{t}$ (either $s r s_{t}$ or $\left.l r s_{t}\right)$. The bootstrap $p$-values of the threshold and unit root tests obtained from these estimated models are reported in Table 3. The order of the lagpolynomial $a(L)$ was selected according to the BIC and Hannan criteria applied to the linear model. This procedure led to a choice of $p=1$ in all cases. For the test of the existence of a threshold effect, the bootstrap $p$-values obtained by constraining $\rho=0$ under the null are exactly the same as the ones obtained for an unconstrained value of $\rho$. Thus, we only report the latter values.

As can be seen from Table 3, the Wald statistics, $W^{T}$, lead us to strongly reject the linear null in favor of a threshold effect for all of the models but the Canadian one when the long-term interest rates are used to define the threshold variable. 
Table 3 : Threshold and unit-root tests, $p-$ Values

\begin{tabular}{l|ccccccc} 
& $\mathrm{d}$ & $W_{T}$ & $R_{1 T}$ & $R_{2 T}$ & $t_{1}$ & $t_{2}$ & AIC \\
\hline & \multicolumn{7}{c}{$Z_{t}=s r s_{t}$} \\
US & 7 & 0.002 & 0.022 & 0.012 & 0.004 & 1.000 & -8.09 \\
UK & 1 & 0.000 & 0.068 & 0.071 & 0.702 & 0.026 & -8.00 \\
FR & 5 & 0.001 & 0.053 & 0.056 & 0.013 & 0.703 & -9.30 \\
DE & 11 & 0.007 & 0.023 & 0.009 & 0.007 & 1.000 & -8.92 \\
CA & 7 & 0.017 & 0.702 & 0.737 & 0.289 & 0.797 & -9.05 \\
IT & 3 & 0.000 & 0.002 & 0.002 & 0.001 & 1.000 & -8.69 \\
JP & 3 & 0.006 & 0.160 & 0.168 & 0.100 & 0.344 & -7.44 \\
& & & & & & & \\
& & & & $Z_{t}=l r s_{t}$ & & & \\
US & 3 & 0.023 & 0.040 & 0.039 & 1.000 & 0.009 & -8.03 \\
UK & 12 & 0.000 & 0.001 & 0.001 & 0.000 & 1.000 & -8.00 \\
FR & 5 & 0.001 & 0.294 & 0.306 & 0.452 & 0.185 & -9.30 \\
DE & 9 & 0.001 & 0.616 & 0.638 & 0.655 & 0.301 & -8.93 \\
CA & 7 & 0.112 & 0.699 & 0.478 & 0.500 & 1.000 & -9.03 \\
IT & 3 & 0.000 & 0.035 & 0.024 & 0.011 & 1.000 & -8.64 \\
JP & 3 & 0.006 & 0.136 & 0.146 & 0.439 & 0.057 & -7.44 \\
\hline
\end{tabular}

Regarding the unit root tests, the models we are interested in are those which reject $i$ ) the unit root null according to the $R_{1 T}$ and $R_{2 T}$ statistics, and moreover $i i$ ) the null of a unit root in the outer regime according to the $t_{1}$ statistics. As mentioned above, the hypothesis of a partial unit root is relevant in this analysis only if the arbitrage area is the one associated with large interest rate differentials in absolute value. When $Z_{t}=s r s_{t}$, the models for the US, France, Germany and Italy match both criteria at the $5 \%$-level. When $Z_{t}=l r s_{t}$, only the UK and Italy satisfy criteria i) and ii). Since there are two admissible models in the Italian case, we present only the results of the model which minimizes the AIC criterion ${ }^{13}$, namely the one with $Z_{t}=s r s_{t}$, but the conclusions remain unchanged when the long-term interest rates are used. The conclusions drawn from the Japanese model with $Z_{t}=s r s_{t}$ are less supportive : the $R_{1 T}$ and $R_{2 T}$ statistics reject the null at the $16 \%$ level only, but the null that $\rho_{1}=0$ is rejected at the $10 \%$ level. For this reason, the results of this model are not reported in Table 4. Finally, the Canadian model is clearly at odds with the others : the unit root null is never rejected.

According to these tests, it appears that all the European countries are consistent with the nonlinear stationary alternative, whereas only half the other countries are so at the $5 \%$-level. This finding may well be related to

13 Remark that in the German case, even though the model with $Z_{t}=l r s_{t}$ is slightly preferred according to the AIC criterion, it does not fulfill criteria i) and ii) mentioned above, which justifies the choice of $Z_{t}=s r s_{t}$. 
the European exchange rate system as well as to the European convergence achieved during the second half of our sample in the perspective of the setting up of the Euro. ${ }^{14}$

Table 4 reports the estimates of the TAR models which allow to reject both linearity and the unit root hypothesis.

Table 4 : TAR model estimates

\begin{tabular}{l|ccccc} 
& $\mathrm{US}$ & $\mathrm{UK}$ & $\mathrm{FR}$ & $\mathrm{DE}$ & $\mathrm{IT}$ \\
\hline outer regime: & & & & & \\
$\hat{a}_{1}$ & 0.15 & $\mathbf{0 . 5 0}$ & $\mathbf{0 . 3 7}$ & $\mathbf{0 . 3 7}$ & $\mathbf{0 . 6 0}$ \\
$\hat{\mu}_{1}$ & $(1.19)$ & $(4.93)$ & $(3.27)$ & $(4.75)$ & $(6.67)$ \\
& $\mathbf{0 . 2 5}$ & $\mathbf{0 . 4 5}$ & $\mathbf{0 . 0 4}$ & $\mathbf{0 . 2 4}$ & $\mathbf{0 . 3 1}$ \\
$\hat{\rho}_{1}$ & $(3.45)$ & $(4.28)$ & $(2.49)$ & $(3.56)$ & $(4.88)$ \\
& $-\mathbf{0 . 0 5}$ & $-\mathbf{0 . 0 9}$ & $-\mathbf{0 . 0 8}$ & $-\mathbf{0 . 0 5}$ & $-\mathbf{0 . 0 7}$ \\
$n_{1}$ & $(-3.47)$ & $(-4.31)$ & $(-2.52)$ & $(-3.56)$ & $(-4.85)$ \\
& 73 & 90 & 68 & 133 & 90 \\
inner regime: & & & & & \\
$\hat{a}_{2}$ & & & & & \\
& $\mathbf{0 . 3 8}$ & $\mathbf{0 . 2 4}$ & 0.05 & 0.21 & 0.17 \\
$\hat{\mu}_{2}$ & $(4.97)$ & $(3.01)$ & $(0.65)$ & $(1.76)$ & $(2.06)$ \\
& -0.07 & -0.02 & 0.06 & -0.14 & -0.09 \\
$\hat{\rho}_{2}$ & $(-1.27)$ & $(-0.27)$ & $(0.82)$ & $(-1.48)$ & $(-1.49)$ \\
& 0.01 & 0.00 & -0.01 & 0.03 & 0.02 \\
$n_{2}$ & $(1.29)$ & $(0.29)$ & $(-0.81)$ & $(1.47)$ & $(1.46)$ \\
& 132 & 110 & 139 & 68 & 119 \\
\hline$Z_{t-\hat{d}}$ & & & & & \\
$\hat{\lambda}$ & $s r s_{t-7}$ & $l r s_{t-12}$ & $s r s_{t-5}$ & $s r s_{t-11}$ & $s r s_{t-3}$ \\
$\hat{\sigma}_{\varepsilon}$ & $2.3 \times 10^{-3}$ & $2.4 \times 10^{-3}$ & $2.0 \times 10^{-3}$ & $1.1 \times 10^{-3}$ & $1.9 \times 10^{-3}$ \\
& 0.017 & 0.018 & 0.009 & 0.011 & 0.013 \\
\hline
\end{tabular}

There are a number of aspects which are worth commenting on. First, the point estimate of $\rho_{1}$ is significantly negative in all cases, and equal to or less than $\mathbf{- 0 . 0 5}$. These results are clearly at odds with the standard linear results, especially given their statistical significance. Second, the point estimates of $\rho_{2}$ are very close to zero (none is statistically significant) and are therefore defining the region in which the real exchange rates are nonstationary. Note that the estimated thresholds are numerically very small and they are smallest for Germany which has the largest number of observations in the outer regime. Basically, our results provide empirical support for Dumas (1992)'s prediction of the link between the real exchange rate and the real interest-rate differential. Indeed, a large real-rate differential corresponds to strong expected reversion in PPP deviations.

14 Subsequent work by Bec, Ben Salem and Rahbek (2004), based on bilateral real exchange rate data, provides some empirical support to the idea that European institutions actually played an important role in the adjustment towards PPP. 
In Table $4, n_{i}$ denotes the number of observations which lie in regime $i$. For all the exchange rates, apart from the German mark, we note that the majority of observations lie in the non-stationary region. However, it is worth emphasizing that for all other currencies, at least $30 \%$ of the total number of observations lies in the stationary region and so our results are not being driven by, say, a few important outliers. The number of observations in the non-stationary region may explain why using a standard linear unit root test will fail to reject the null, as pointed out by Taylor (2001).

As we have noted, a key conclusion to emerge from the recent PPP literature is that mean reversion speeds are too slow to be consistent with a traditional form of PPP. In order to compare our adjustment speeds with others reported in the literature, we compute the implied half-lives for the outer regime from the impulse response functions resulting from a unit shock occurring at date 1 in this regime. The latter are reported in Figure 1. The implied half-life then obtains when the impulse response function crosses the horizontal line drawn at $z_{t}=0,5$.

Figure 1 : Half-lives in the outer regime

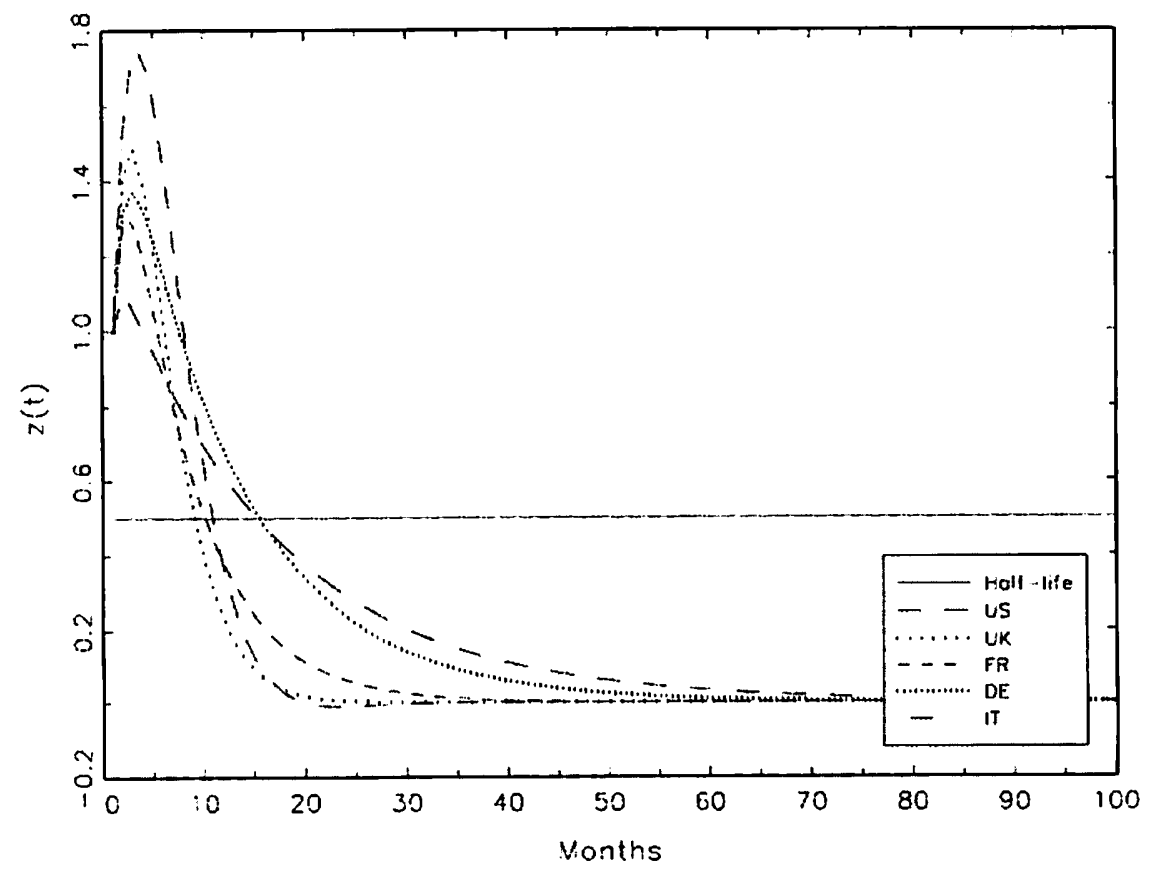

In the mean-reverting regime, the half-life typically ranges between ten and sixteen months. The lowest ones are obtained for the UK, France and Italy, where they hardly reach a year. These are extremely rapid when compared to the kind of half-lives found in linear empirical studies. Of course, 
this stems from the fact that they correspond to the outer regime only. Indeed, since the root of the inner regime is never significantly different from zero according to the $t_{2} p$-values reported in Table 3 , the corresponding theoretical half-life is infinity in this area. Nevertheless, our figures are entirely consistent with a traditional form of PPP, once the trading costs are taken into account : in the no-trade area, slow adjustment is expected if any, whereas in the trading area, international arbitrage provokes quite quick adjustment. It is worth noting that these half-lives are comparable with the adjustment speeds found by others in the nascent nonlinear exchange rate literature. For example, Obstfeld and Taylor (1997) find a half-life of typically 12 months for aggregate CPI-based real exchange rates.

\section{Conclusions}

In this paper we have re-examined the nonlinear properties of the real exchange rate in a B-TAR framework. In contrast to other B-TAR studies, we explicitly address the stationarity properties of the variable used to define the bands. In particular, we have used the real interest differential (a stationary variable) to define the threshold bands. Seven real effective exchange rates were analysed for the period January 1980 to December 1997 . We proposed the joint application of two tests (for a threshold and for a unit root) which allow us to distinguish nonlinearity from non-stationary processes.

Our empirical study revealed a clear nonlinear dynamics for the seven real exchange rates. In five cases, the nonlinear representation rejects the random-walk hypothesis for the real exchange rate process. One very appealing aspect of our work is that we obtained quite fast half-lives compared to linear models of the real exchange rate.

In sum, using new developments in econometric theory, specifically designed to tackle non-stationarity issues in a nonlinear setup, our study provides further support for the nonlinear mean reverting dynamics of real exchange rates suggested in recent empirical research. Moreover, we interpret our findings as indicating the relevance of the real interest differential in governing the time series properties of the real exchange rate, a possibility which had previously only been explored in a linear setup. 


\section{References}

Alexius, A. (2005), "Productivity shocks and real exchange rates", Journal of Monetary Economics, 52, pp. 555-566.

Andrews, D. (1991), "Heteroskedasticity and autocorrelation consistent covariance matrix estimation", Econometrica, 59, pp. 817-858.

Bec, F., M. Ben Salem and A. Rahbek (2004), "Nonlinear adjustment towards the Purchasing Power Parity relation: a multivariate approach", Manuscript, CREST, Paris.

Bergman, U. and J. Hansson (2005), "Real exchange rates and switching regimes", Journal of International Money and Finance, 24, pp. 121138.

Berka, M. (2004), "General equilibrium model of arbitrage trade and real exchange rate persistence", Manuscript, University of British Columbia, Vancouver.

Bessec, M. (2002), "Mean reversion versus adjustment to PPP : the two regimes of exchange rates dynamics under the EMS, 1979-1998", Economic Modelling, 20, pp. 141-164.

Caner, M. and B. Hansen (2001), "Threshold autoregression with a unit root", Econometrica, 69, pp. 1555-1596.

Coughlin, C. and K. Koedijk (1990), "What do we know about the longrun real exchange rate?", St. Louis Federal Reserve Bank Review, 72, pp. 36-48.

Dickey, D. and W. Fuller (1981), "Likelihood ratio statistics for autoregressive time series with an unit root", Econometrica, 49, pp. 1057-1072.

Douc, R., A. Guillin and E. Moulines (2004), "Limit theorems for subgeometric Markov chains", Manuscript, École Polythechnique, Palaiseau.

Dumas, B. (1992), "Dynamic equilibrium and the real exchange rate in a spatially separated world", Review of Financial Studies, 5, pp. 153180.

Edison, H. and B. Pauls (1993), "A re-assessment of the relationship between real exchange rates and real interest rates : 1974-90", Journal of Monetary Economics, 31, pp. 165-187.

Edison, H. and W. Melick (1999), "Alternative approaches to real exchange rates and real interest rates : three up and three down", International Journal of Finance and Economics, 4, pp. 93-111.

Enders, W. and C. Granger (1998), "Unit-root tests and asymmetric adjustment with an example using the term structure of interest, rates", Journal of Business and Economic Statistics, 16, pp. 304-311.

Froot, K. and K. Rogoff (1995), "Perspectives on PPP and long-run real exchange rates", in G. Grossman and K. Rogoff (eds.), Handbook of International Economics vol.3, Amsterdam, Elsevier/North-Holland, pp. $1647-1688$. 
Gagnon, J. (1996), "Net foreign assets and equilibrium exchange rates : panel evidence", International Finance Discussion Paper $n^{\circ}$ 574, Board of Governors of the Federal Reserve System, Washington.

Gonzalez, M. and J. Gonzalo (1998), "Threshold unit root models", Manuscript, University Carlos III, Madrid.

Gottschalk, J. (2001), "Measuring expected inflation and the ex-ante real interest rate in the Euro area using structural VARs", Working Paper $\mathrm{n}^{\circ}$ 1067, Kiel Institute of World Economics, Kiel.

Granger, C. and T. Terasvirta (1993), Modelling non-linear economic relationships, Oxford, Oxford University Press.

Haggan, V. and T. Ozaki (1981), "Modelling nonlinear random vibrations using an amplitude-dependent autoregressive time series model", Biometrika, 68, pp. 189-196.

Henry, O. and N. Olekalns (2002), "Does the Australian dollar real exchange rate display mean reversion?", Journal of International Money and Finance, 21, pp. 651-66.

Kilian, L. and M. Taylor (2003), "Why is it so difficult to beat the random walk forecast of exchange rates?", Journal of International Economics, 60, pp. 85-107.

Krugman P., (1989), Exchange rate instability, Cambridge MA, MIT Press.

Krugman, P. (1991), "Target zones and exchange rate dynamics", Quarterly Journal of Economics, 106, pp. 669-682.

Kwiatkowski, D. P. Phillips, P. Schmidt and Y. Shin, (1992), "Testing the null hypothesis of stationarity against the alternative of a unit root. How sure are we that economic time series have a unit root?", Journal of Econometrics, 54, pp. 159-178.

MacDonald, R. (1995), "Long-run exchange rate modeling: A survey of the recent evidence", International Monetary Fund Staff Papers, 42, pp. 437-489.

MacDonald, R. (1999), "What do we really know about real exchange rates ?", in R. MacDonald and J. Stein (eds), Equilibrium exchange rates, Amsterdam, Kluwer.

MacKinnon, J. and H. White (1985), "Some heteroskedasticity-consistent covariance matrix estimators with improved finite sample properties", Journal of Econometrics, 29, pp. 305-325.

Mark, N. (1999), "Fundamentals of the real dollar-pound rate 1871-1994", in R. MacDonald and J. Stein (eds), Equilibrium exchange rates, Amsterdam, Kluwer.

Meese, R. and K. Rogoff (1988), "Was it real? The exchange rate-interest differential relation over the modern floating-rate period", The Journal of Finance, 43, pp. 933-948.

Michael, P., A. Nobay and D. Peel (1997), "Transactions costs and nonlinear adjustment in real exchange rates : an empirical investigation", Journal of Political Economy, 105, pp. 862-879. 
Obstfeld, M. and A. Taylor (1997), "Nonlinear aspects of goods-market arbitrage and adjustment: Heckscher's commodity points revisited, Journal of the Japanese and International Economies, 11, pp. 441479.

Officer, L. (1976), "The purchasing power parity theory of exchange rates: a review article", IMF Staff Papers, 23, pp. 1-60.

Phillips, P. and P. Perron (1988), "Testing for unit root in time series regression", Biometrika, 75, pp. 335-346.

Pippenger, M. and G. Goering (2000), "Additional results on the power of unit root and cointegration tests under threshold process", Applied Economics Letters, 7, pp. 641-644.

Rogoff, K. (1996), "The purchasing power parity puzzle", Journal of Economic Literature, 34, pp. 647-668.

Schnatz, B., F. Vijselaar and C. Osbat (2004), "Productivity and the ('synthetic') Euro-dollar exchange rate", Review of World Economics, 140, pp. 1-30.

Sercu, P., R. Uppal and C. Van Hulle (1995), "The exchange rate in the presence of transaction costs : implications for tests of purchasing power parity", The Journal of Finance, 50, pp. 1309-1319.

Shin, D. and O. Lee (2001), "Tests for asymmetry in possibly nonstationary time series data", Journal of Business and Economic Statistics, 19, pp. 233-244.

St-Amant, P. (1996), "Decomposing U.S. nominal interest rates into expected inflation and ex ante real interest rates using structural VAR methodology", Working Paper $n^{\circ}$ 96-2, Bank of Canada, Ottawa.

Taylor, A. (2001), "Potential pitfalls for the PPP puzzle? Sampling and specification biases in mean-reversion tests of the LOOP", Econometrica, 69 , pp. 473-498.

Throop, A. (1994), "A generalised uncovered interest rate parity model of real exchange rates", Manuscript, Federal Reserve Bank of San Fransisco, San Fransisco.

Tsay, R. (1998), "Testing and modeling multivariate threshold models", Joumal of the American Statistical Association, 93, pp. 1188-1202.

Uppal, R. (1993), "A general equilibrium model of international portfolio choice", The Journal of Finance, 48, pp. 529-553. 